\title{
"Looking for the blue, the yellow, all the colours of the rainbow": The value of participatory arts for young people in social work practice
}

\author{
Amber Walls, Kelsey L. Deane, and Peter J. O'Connor University of Auckland, Aotearoa New Zealand
}

\begin{abstract}
INTRODUCTION: Emerging from a flourishing field of practice overseas, the growing evidence base for participatory arts engagement demonstrates numerous benefits for young people's health and wellbeing. In Aotearoa New Zealand, participatory arts engagement is under-valued and under-resourced despite local practice examples suggesting that it deserves further attention.

METHODS: Focusing on a case example from an Auckland-based creative arts participation project geared to promote the positive mental health and wellbeing of marginalised young people, two focus groups were conducted to explore how participants felt arts engagement contributed to their wellbeing. Participatory arts activities were integrated within the focus group process to enable creative expression of their voices.

FINDINGS: The youth voices unearthed through this research indicate that an arts-based approach can be used as a powerful tool in promoting youth wellbeing and this offers a significant promise for addressing local policy priorities.

CONCLUSION: We suggest that participatory arts engagement deserves further investment and research to explore further application in social practice in Aotearoa New Zealand.

KEYWORDS: participatory arts, youth, mental health, wellbeing, Aotearoa New Zealand
\end{abstract}

Participatory arts engagement can be used as a powerful evidence-informed approach in social work practice. We suggest that it is an under-developed and under-utilised area of practice in Aotearoa New Zealand, in comparison with many other nations where participatory arts engagement has been the subject of research, investment and policy leadership and has flourished over the last two decades (Pegasus Health, 2014). We argue that there is a growing and credible evidence base, and a wealth of practice examples (Clift \& Camic, 2016; Macpherson, Hart, \& Heaver, 2015; Pegasus Health, 2014;
Putland, 2012; Secker, Hacking, Spandler, Kent, \& Shenton, 2007; White, 2009) that could be utilised to address policy priorities and practice gaps in the local context. In this article, we focus on policies and practice pertaining to youth mental health and wellbeing, an issue of national concern and the subject of current investigations exploring new ways of working to better meet the needs of our youth population (Youth Mental Health Project, 2012).

In the absence of an established local research base, this article first provides a
AOTEAROA

NEW ZEALAND SOCIAL WORK 28(4), 67-79.

CORRESPONDENCE TO: Amber Walls amberwalls2@gmail.com 
brief overview of the international picture of participatory arts in mental health practice and highlights key conclusions drawn from the international evidence base. We then focus on a local case study project in central Auckland-Express Yourself - that uses arts participation to promote positive outcomes for marginalised young people in alternative education, mental health and addictions services. We draw on findings collected from two focus group discussions with participants to demonstrate the ways through which arts participation has enhanced their lives and conclude with important considerations for others interested in using participatory arts in social work practice in Aotearoa.

\section{Participatory arts engagement and its many forms}

Participatory arts are being used successfully to improve wellbeing throughout advanced Western economies. Substantial growth in this area of activity over the last two decades, particularly in the United Kingdom, the United States of America, Canada and Australia (Clift \& Camic, 2016), has been accompanied by the emergence of a diverse, evidence-informed body of practice (Clift, 2012; Clift \& Camic, 2016; Department of Health, 2011; Hacking, Secker, Spandler, Kent, \& Shenton, 2008; Macpherson et al., 2015; Pegasus Health, 2014; Putland, 2012; Secker et al., 2007; White, 2009; Wreford, 2016). The power of the arts and creative expression as a tool for youth engagement and development has been a particular area of growth, inspiring localised and national initiatives across education, youth justice, social, health and community environments (Clift \& Camic, 2016).

The field is diverse and is represented by many related terms including: community arts, participatory arts, arts in justice settings, arts in health and wellbeing, socially engaged arts, community cultural development and applied arts. The variations in term are often the result of the location or context. For the purpose of this article, which focuses on youth mental health and wellbeing, we primarily draw from the research base represented under the arts in health and wellbeing banner. However, the practices are by no means exclusive to healthcare environments. In fact, they are described as taking place largely in community settings addressing complex social, cultural and economic determinants at both individual and systemic levels (White, 2009). Further, this practice is synonymous with a social inclusion, empowerment and social justice lens (Clift, 2012), committed to transformative processes and seeks to build relationships and alliances for personal and social changes (White, 2009).

\section{The international picture of arts in health practice}

The rapid growth of arts in health practices in the West over the last two decades has been described as a "small-scale global phenomenon" (White, 2016, p. 41), and is supported by a growing interdisciplinary workforce, regional and national networks and a thriving academic community (Clift \& Camic, 2016; White, 2009). Between 2013 and 2014, thirteen international conferences exploring emerging practices were held across Australia, Europe, Scandinavia, the United States of America, Canada, South Africa and the Middle East (Clift \& Camic, 2016). In the United Kingdom and Australia in particular, the field has flourished and continued to attract public investment despite global recession and an overall reduction in arts funding. In the United Kingdom, arts in health practice is well established across national provider networks and is acknowledged as a credible health-promotion tool in terms of public policy and financial investment priorities (ACE, 2014; Department of Health, 2011). The last decade has seen a number of large region-wide arts in health and wellbeing initiatives, in London and the Northwest, in particular. Arts on prescription schemes (i.e. referral to arts programmes via GP practices, primary and secondary care providers) have flourished, and are described as now being 
commonplace (White, 2016). In Australia, arts in health practice has also gathered momentum around the community arts movement and is championed by a National Arts and Health Framework (NAHF), released in 2013 and endorsed by all Australian regional arts and health ministers, an active national network, an annual international conference and a rapidly growing research base (Wreford, 2016).

The growing body of arts in health research internationally highlights a wide spectrum of positive social, educational and health outcomes (Bungay \& Vella-Burrows, 2013; Clift, 2012; Clift \& Camic, 2016; Department of Health, 2007; Department of Health, 2011; Ings, Crane, \& Taylor, 2012; Macpherson et al., 2015; Pegasus Health, 2014; Putland, 2012; Secker et al., 2007; White, 2009; Wreford, 2010). A recent meta-analysis of the arts in health evidence base published in the Journal of Social Work established the link between visual arts interventions and improved mental health resilience in young people with complex needs. Accordingly, Macpherson et al. (2015) concluded that arts for health approaches offer much promise to social work practice.

In Australia, a 2012 meta-analysis of the international evidence case was commissioned to support the development of the National Arts and Health Framework. It concluded that the evidence for the inclusion of arts in health was persuasive (Putland, 2012). This report is a useful guide, highlighting evidence of impacts across a continuum of known determinants of health and wellbeing. Of particular relevance to this study, the report highlights evidence linking the relationship between community-based arts participation and personal development (for example, efficacy, mastery, empowerment and quality of life); transferable skills for relationships, health literacy, coping and employability; physical health improvements; social engagement and cohesion (for example, support, empathy, belonging, group identity, pride and tolerance) and community building (for example, engagement and cooperation) in population level preventative practice. With at risk communities specifically, these benefits were linked to improved mental health, health literacy and healthy lifestyles (resulting in reduced need for medication and healthcare), and increased capacity for vulnerable people to make changes in their lives (Putland, 2012). Notably, in the context of an international evidenceinformed policy making environment that emphasises economic arguments, the review notes the recent focus on costbenefit analysis in the United Kingdom, the United States of America and Australian arts in health research. Importantly, the results of these analyses are favourable. For instance, an Australian study found that an arts-based approach in the treatment of depression yielded similar improvements at cheaper financial cost than more traditional alternatives (Craemer, 2009).

\section{The local picture of arts in health practice}

Despite this global growth in research and practice, the use of participatory arts for youth wellbeing is still described as being relatively under-resourced and lacking recognition in social, health and cultural policy (Clift \& Camic, 2016). We suggest that this is particularly true in Aotearoa New Zealand, where practice is considerably less developed in comparison with Australia, the United States of America, Canada, United Kingdom, Ireland and other European countries. Although excellent examples of activity exist, the field has not gained the same momentum.

Signalling growing interest among health providers, a recent report was commissioned by the Aotearoa New Zealand primary care group, Pegasus Health. The review concludes that only a small number of localised arts for wellbeing projects are funded through sustained sources (public health or government contracts), and acknowledges the comparative lack of local development in contrast to the promising 
potential confirmed by the international evidence base. It suggests that a number of overseas studies are encouraging, including projects with at risk young people leading to significant benefits to psychosocial health, improved self-esteem, confidence, selfefficacy and overall quality of life (Pegasus Health, 2014).

Although the Mental Health Foundation and more recently Creative New Zealand acknowledge the value of arts in wellbeing and both host a number of online research and advocacy reports, these are almost exclusively generated overseas. One of the few areas of significant praxis development has been the use of applied theatre programmes in mental health promotion (Maunder, 2013), encompassing theatre work that takes a wide view of the social and political determinants of health ( $\mathrm{O}^{\prime}$ Connor, 2014). Nevertheless, unlike the environment described overseas where practice has flourished with the support of a professional and policy infrastructure and strategic leadership, in the local context, we lack this infrastructure and consequently practice has been fragmented and slower to develop.

\section{Current research}

We acknowledge the importance of learning from overseas developments, but also recognise the necessity of generating contextually specific practice, which meets the needs of communities in Aotearoa. We offer here, as a practice example, some of the initial learning we have gained from research with an Auckland-based projectExpress Yourself-that uses creative arts participation to promote positive outcomes among vulnerable youth populations, including those in schools, alternative education, mental health, addictions and community-based contexts. Express Yourself is the subject of an ongoing doctoral research study exploring creative arts engagement as a tool in promoting youth wellbeing. The overarching research project aims to produce a locally contextualised, culturally attuned model of participatory arts practice focussed on promoting youth mental health and wellbeing, and has involved an extensive process of enquiry, programme theorybuilding and evaluation co-design with the project community (staff, participants, partner or stakeholder organisations). We are intentionally seeking, through this component of the research, to create knowledge which values the self-determined experiences, ideas and identities of youth participants alongside the established evidence base and, as it is beyond the scope of this article to capture all stakeholder perspectives, here we focus exclusively on the methods and results involving the youth project participants. The objective of this study was to surface youth participant perspectives of the impact of experiences offered through Express Yourself in view of the international evidence base, as well as the specific features of the project itself.

\section{The case example}

Express Yourself is a philanthropically funded multi-arts project working across Auckland to promote positive mental health in vulnerable young people aged 13-24. It is delivered by Toi Ora, a non-governmental organisation (NGO). In addition to participatory arts practice, Express Yourself is also informed by the theories and practice of Positive Youth Development (PYD). PYD is an evidence-informed, strengths and systems-based approach to understand and work with young people that stems from developmental relations systems theory. Developmental systems theory emphasises plasticity in human development as a result of ongoing and reciprocal person-environment interactions. When a person's inherent strengths are aligned with a resource rich context, positive development is supported (Lerner et al., 2012). The primary focus when taking a PYD approach is thus to build personal strengths while connecting youth to an asset-rich environment to reduce risks and ultimately promote thriving. Often, this is through structured youth development programmes (Lerner et al., 2012). 
Express Yourself works at both preventative and intervention ends of the spectrum, but always with populations who are experiencing life challenges. Participants are referred into the project via specialist youth mental health and addictions services. They are often struggling to cope with a variety of mental health conditions, and many are struggling to cope with relationships, social environments, education or work. Express Yourself offers creative projects; one-toone mentoring supporting individualised pathways into further educational, training and employment; supported artist workspaces; youth internships and a platform for youth-led initiatives. It is facilitated by a team of experienced youth development and creative practitioners spanning visual, digital and literary arts, music, performance and dance. Express Yourself is described in project documents as setting out to inspire young people to grow, learn and deal with life challenges. It aims to do this by providing a safe space, structure and creative processes to work alongside others to reflect on life situations, build personal skills and resources, and draw from supportive networks to achieve self-determined goals.

\section{Methods}

\section{Design}

Two focus groups were conducted with participants aged between 18 and 24 who had taken part in at least one of the Express Yourself projects. Both focus groups aimed to elicit the youth participants' authentic experiences of the creative projects they had been involved with so as to inform the collective programme theory of change for the broad research project. Key questions that were asked included: "What does Express Yourself offer young people? What kind of person would benefit from coming to a project like this? What could they hope to get out of the experience? What does Express Yourself do to make these things happen? What are the most important aspects of the project that help it to work or that stop it from working?"
The questions did not seek to solicit answers about personal experience, but encouraged participants to draw from their knowledge of the project to hypothesise about its value to young people broadly. Participatory arts activities were employed in both groups to enable young people to articulate responses using a variety of media.

Ethical approval for this research was granted by the authors' institutional ethics committee. We carefully considered how to create a safe environment for vulnerable young people in a focus group situation. Great care was taken to explain what participation would entail and what could and could not be promised in this environment, including for example, the guarantee that other participants would not breach confidentiality.

\section{Focus group one: Participants and procedure}

The participants for focus group one were identified using a convenience sampling strategy. All participants who were registered in an Express Yourself project at the time of the workshop were invited. The first author visited the project in person and described the research goals and participation process. Then, she distributed Participant Information Sheets outlining the potential benefits and risks of the project and the rights of each participant. Six out of eight young people aged 18-20 consented to take part. Participants self-identified as one male and five females; one Māori, one Pasifika, one dual heritage (Māori and NZ European), one Asian and two NZ Europeans. All participants had been introduced to Express Yourself via Community Mental Health or Addictions Services.

This focus group engaged in individual visual art-making alongside group discussion, including painting, collage and mask-making. Participants chose which of these media they preferred and represented ideas visually and verbally, often using metaphor as a way of expressing difficult 
emotions. They were invited to share interpretations voluntarily with the group as they felt safe to do so. As most of the group knew each other well, they responded to each other's comments and added their own perspectives.

\section{Focus group two: Participants and procedure}

Focus group two was conducted 10 months later with a new group of five participants aged 20-23, who had taken part in two different Express Yourself projects. Participants self-identified as two males and three females; one dual heritage (Māori and NZ European), one Asian and three NZ Europeans. All participants had been introduced to Express Yourself via Community Mental Health or Addictions Services, except one who self-referred. This focus group aimed to capture both the views of a slightly older age group and explore the project's critical processes in depth (i.e. not just what the project achieved but how). The groups were invited by the first author via a visit to the group (focus group one) and telephone (focus group two). She followed up initial expressions of interest with the distribution of participant information sheets. Five out of the eight participants invited expressed interest, with three being unavailable on the day (one was out of town and the other two were re-admitted into hospital prior to the day).

The second youth focus group used a large two-metre high tree as a visual metaphor to explore the idea of healthy eco-systems. The same questions were asked as in the first focus group, this time using additional metaphorical devices to further illustrate ideas such as watering cans, the weather, roots, branches and fruit. Through a series of exercises, participants were asked to add drawings and text to the tree as a means of exploring broadly what Express Yourself offered young people and identifying the critical project practices and processes that enabled or prevented this from happening. Discussion about the tree's broader environmental eco-system prompted further exploration about wider societal conditions that affect mental health and wellbeing.

\section{Analysis}

The data collected from the two focus groups were analysed separately using thematic analysis as described by Braun and Clarke (2013). The findings from each focus group were then cross-referenced to identify overlapping themes. There was considerable consistency between the themes identified in each focus group, although the second workshop gathered more individual responses.

\section{Findings}

The focus group data demonstrated that the young people benefitted greatly from their creative engagement in Express Yourself. Of note, the project conditions that enabled their positive development were remarkably different from those experienced in their day-to-day lives outside the project. The emerging themes are represented by headings below.

\section{Arts participation: Relaxation, refuge, a legal high and providing purpose}

The most common motivation for participating in the project was to help with stress, anxiety and depression. Express Yourself provided "a reason to get out of bed". All participants agreed that arts participation was good for their wellbeing. Some described the process of absorption in art-making as therapeutic and enjoyable, enabling time out from life chaos. Others described it as a useful aid for organising and reflecting on thoughts, whereas others said that they learned self-care strategies-"ways to manage my wellbeing". This included, for example, "mindfulness through art" or [having fun] not getting high. Individuals described feeling less anxious when they left (Figure 1). 


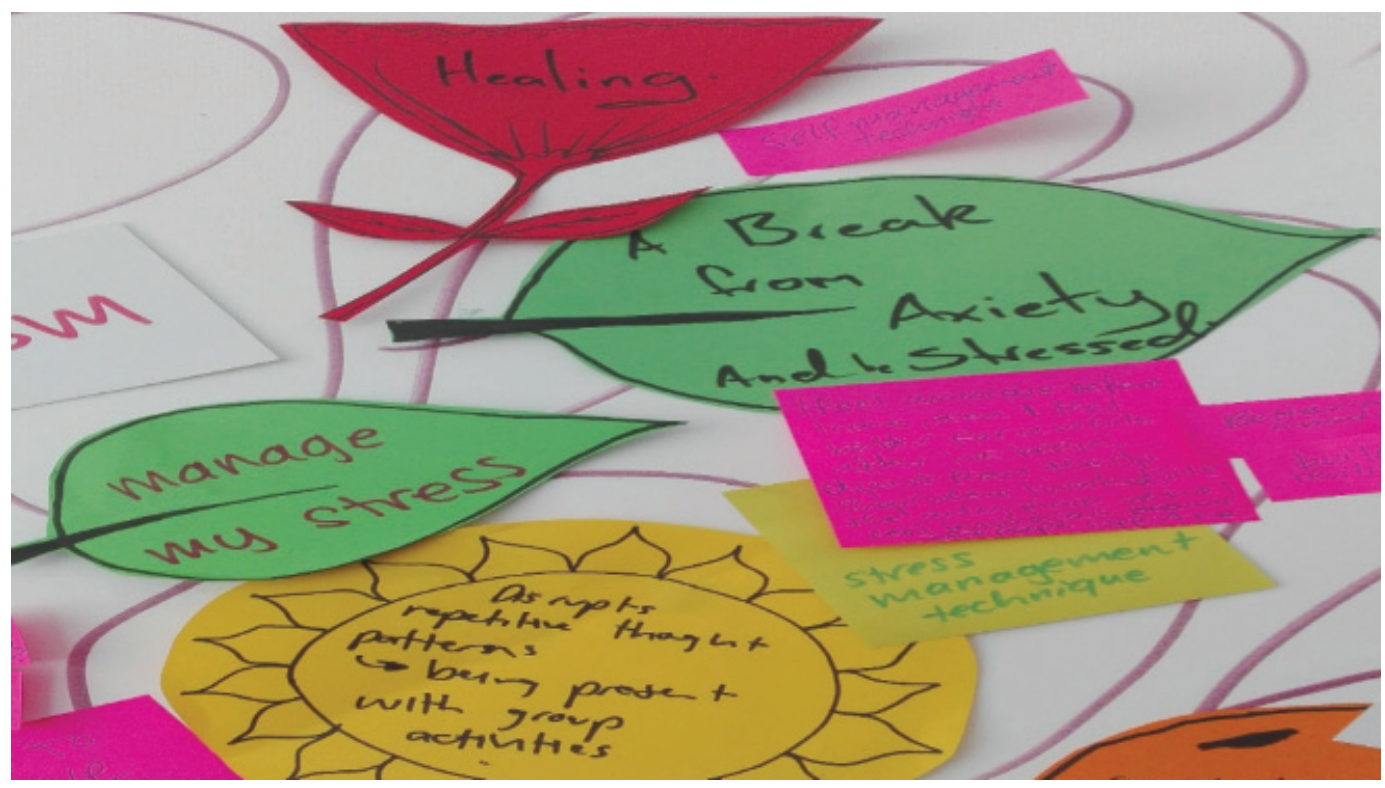

Figure 1: Creative expressions from youth focus group: Arts as a therapeutic tool.

\section{Creative experimentation and play: Fuel for the soul and liberation from shitty adult rules}

Both groups described intensive social pressures, either to do with paying rent, surviving every day, "getting some peace" or "feeling like I don't fit in". The second focus group (with 20- to 23-year-olds) collectively articulated an overwhelmingly negative picture of wider society,

attributing their stress to exclusionary and competitive social values. One participant argued: [out there] "it's all rules and you can't do that... [here] it's all yes you can do that". Another said that "adults, they teach you life sucks, get used to it". Another stated that "adult shitty rules [are] eating our souljoy" (Figure 2). Several participants described the creative art-making process as a liberating antidote to this. A key factor in this was articulated as the experimental and playful nature of activities. Participants said that they came to Express Yourself to "play, have fun, splash colour around", experiment and "just create" without fear of failure. Both focus groups agreed that the project offered a space that enabled achievement in contrast to other aspects of their life: "there's no one to put you down, tell you you've taken a bum photo". Other comments included "Here there are no right or wrong outcomes-just different" and "it's a positive space shared by positive people". The project was described consistently as a sanctuary, a place of hope and imagination, as explained by one participant: [Express Yourself] "is for people with a different view on the world". Others claimed, "it gives me souljoy", and "[it's] for people looking for the blue, the yellow, all the colours of the rainbow... you can just look for the grey or you can look for the blue".

\section{Creative storytelling and critical reflection: Finding a voice and reframing life stories}

Individual participants in both focus groups described how the mixture of critical reflective exercises used each week alongside creative storytelling (through visual images, drama, animation or music) enabled them to reflect on life experiences and share challenging stories with peers in a safe way. They explained that sometimes 


\section{QUALITATIVE RESEARCH}

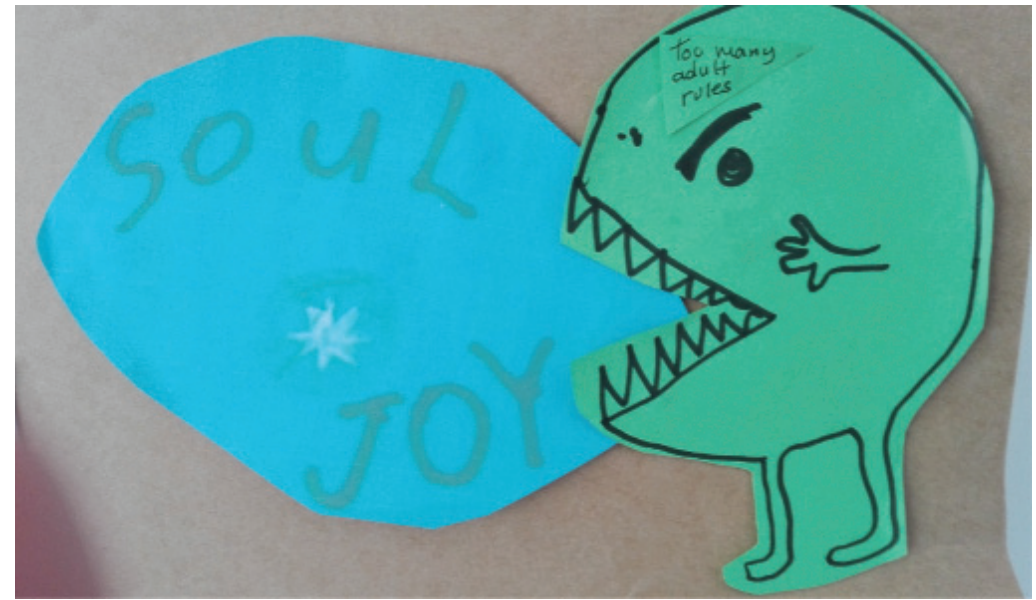

Figure 2: Creative expression from youth focus group: "Shitty adult rules are eating our souljoy".

\section{Relationships: Reciprocal (ako), empowering, human and 'youth- powered'}

Participants unanimously described how relationships established in the project enabled them to feel valued and validated, for example, "I'm completely accepted for who I am here". They felt the art-making processes where everyone was "doing it together" played a significant role in this, allowing everyone to feel equally valued, and enabling relationships to be transformed from client versus provider into co-learners or whānau, counteracting hierarchical and institutional barriers: "you do it with us [...] you take risks and look silly too so it makes me feel brave and I know no one will laugh". Participants in focus group two agreed with the comment "we are all artists here [...] no-one better or more important than anyone else". One participant in this group stated that everyone acts "human, not like some robot who wants to tick off a form saying they cared", while others agreed with the comment that we are all whānau here. One participant said that it felt good when his support worker attended the project too and was asked to take part as an equal: "it made her seem much more human".

\section{Belonging and connection: A stigma free, youth-friendly space}

Participants described how the project enticed them out of isolation, and supported them to face social anxieties and practice relationship skills. They universally described a strong sense of belonging and connectedness to the Express Yourself community. Whakawhanaungatanga (relationship building and kinship) were identified as a crucial feature of the project, not just in reducing isolation, but also in creating opportunity to spend positive time with people their own age "going through stuff too" (Figure 3). Discussion in both groups revealed high levels of isolation and social anxiety. Individuals talked about the "lion face" or bravery required to participate. The arts practice and studio environments 
were both identified as strong enablers in this process, either by allowing the participants to negotiate their engagement in a way that felt safe (for example, by being able to slip easily in and out of self-led or group activity), or because they saw being part of an art group as less stigmatising than participating in other support services. Discussion revealed a common perception that it was important to be able to share a positive common interest first, and not be labelled for perceived failure.

Participants also described how the lowstress environment enabled them to reconnect with people, build confidence, learn new skills and get ready to enter or go back to education or work. Some participants described how they felt unable to attend other groups or support services, which might achieve these goals, explaining that the arts were more appealing and more able to accommodate their personal needs.

\section{Youth-powered: Enabling autonomy and self-determination}

Participants described how the project's youth-led philosophy and practice methodology enabled them to build skills and see themselves as people with something to offer, as leaders. One young person described how they were asked to lead an arts activity and share their ideas. They discovered that they were "actually quite a leader". Another stated that "I have lots of ideas but no-one listens to them usually". One participant commented that the project was "like stabilisers on a bike... yeah, that's what it does... like it gives me confidence to have a go and when no-one laughs I try again... and then, yeah, like I realise I can do it". One participant explained that making his art had enabled him to "say it like it was... in his own voice... in his own way '[instead of]' other people telling him how he was and what should happen". The comment was met with nods of agreement in the group affirming how much the opportunity to self-represent and tell their own stories using images, music, film and poetry was valued.

\section{Discussion}

This investigation into the youth voices of Express Yourself aimed to uncover the potential benefits of participatory arts in health practice and the specific practice features that promote health and wellbeing for young people in the Aotearoa New Zealand context. The intention was to assess if local evidence would align with the favourable evidence produced overseas. The youth focus group participants involved in our research certainly perceived substantial benefits from participation in arts activity, claiming that their engagement in Express Yourself was therapeutic - it gave them a refuge from the stress and pressure they constantly face in other domains of their lives; it also made them feel valued, empowered and connected. Although it is beyond the scope of this study to evaluate long-term impact, participants did speak about practising skills in the project for application in wider settings.
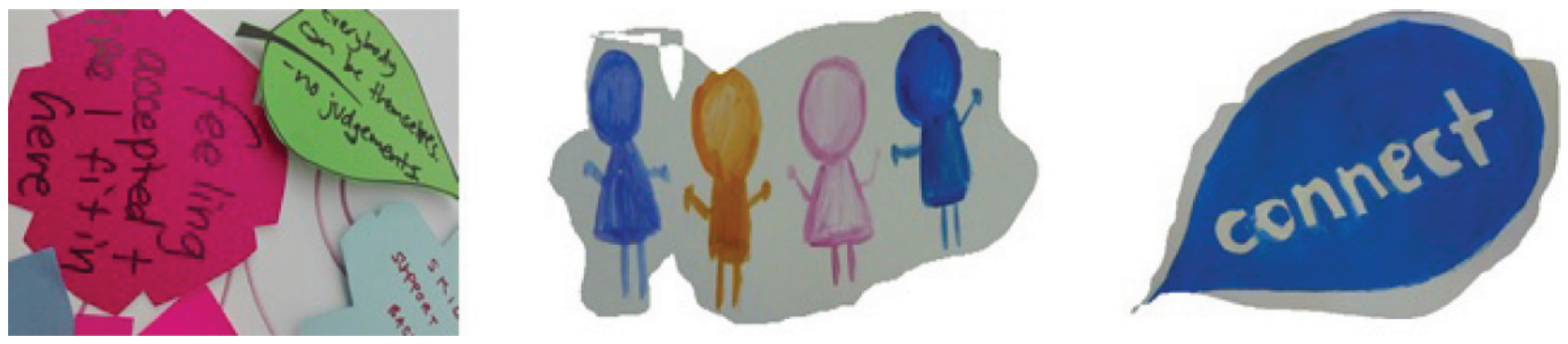

Figure 3: Creative focus group expressions: Connection and belonging. 
Importantly, their self-reported benefits converge with evidence-based indicators of positive mental health and wellbeing identified in the international literature. Putland's (2012) meta-analysis, for instance, revealed positive impacts of arts in health practice on sense of achievement, social participation, belonging and transferable skills. Young people's suggestions about why their experiences had an impact also resonate with processes advocated in the international practice. For example, what works in designing stigma-free youth mental health services according to Australian, Irish and United Kingdom researchers are services that are optimistic, preventative and promote peer relationships and daily living skills such as stress management and self-worth (McGorry, Bates, \& Birchwood, 2013, p. 202).

Some focus group participants described their arts participation as feeding their soul, signalling spiritual benefits that resonate with this critical dimension of the holistic wellbeing found in Māori and Pasifika models of health advanced by Durie (1985) and Pulotu-Endemann (2001). Similarly, in discussing the features of the experience that enabled these outcomes, concepts that strongly reflected other Māori values such as whakawhanaungatanga (interpersonal connectedness) and ako (teaching and learning reciprocity) were identified. Of note, many of these features were inherently tied to the arts-based aspects of the Express Yourself experience. This is not surprising given that the Pegasus Health review also highlights synergies between the philosophical foundation of arts in health and wellbeing and indigenous Māori concepts of holistic wellbeing.

Findings are also consistent with the international youth engagement literature which reminds us that the arts are a powerful motif in young people's lives and a powerful tool for engagement (Ungar, 2013); that the arts are languages young people speak as everyday ways of belonging to a community "through [...] Music, film,
YouTube, dance, magazines" (HickeyMoody, 2013, p. 1). In addition, the benefits that participants described clearly exhibit well-recognised outcomes targeted by PYD programmes such as confidence, competence and connection (Lerner et al., 2012). Further, the features of their arts-based experiences are evident in well-known PYD frameworks, which emphasise the importance of supportive and empowering contexts and caring, competency-enhancing relationships (Lerner et al., 2012). The connection of the arts-based processes to PYD is notable given recent Aotearoa New Zealand-based evidence of the connection between PYD practices and resilience in vulnerable youth (Sanders \& Munford, 2014).

\section{Study limitations and strengths}

Evidently, this study was greatly limited in scope with its exclusive focus on one case example and the inclusion of only 12 participants across 2 focus group discussions. We therefore acknowledge that any extrapolations of the findings to other participatory arts initiatives in the Aotearoa New Zealand context should be undertaken with caution. Further investigation is needed to ascertain the generalisability of the effects. In addition, evaluating the long-term impacts of Express Yourself and other projects using similar participatory arts processes is an area that could be fruitfully explored. Participants in our focus groups also described the significant factors beyond their control in their wider socioecological environment that negatively affected their wellbeing, what we might consider factors driven by the dominant neo-liberal ideologies of the current time. They believed the valued processes in Express Yourself were an antidote to this, offering more open-ended, unpredictable, experimental possibilities. We are unable to explore this further here, but would like to acknowledge this finding as reinforcing the substantial systemic challenges facing vulnerable youth today and the need for further research and action at the macrolevel. 
These limitations aside, the convergence of our findings with the international literature provides promise for the value of participatory arts engagement in Aotearoa New Zealand. The creative approach employed to gather focus group data is also seen as a strength of the research. Since the process mirrored arts-based processes familiar to and valued by participants, who may otherwise struggle to express their ideas through a more traditional interviewing approach, rapport with the researcher was enhanced and the participants were comfortable opening up. We suggest that the availability of multiple media through which their voices could be expressed also provided additional richness to the findings (Figures 1-3).

\section{Implications}

\section{Policy implications}

As illustrated earlier, participatory arts in social practice has flourished overseas in comparison to the local picture. We suggest that this is largely due to an unfavourable practice and policy environment. In the arts sector, national policy has historically emphasised art-form development rather than participatory practices, though more recent developments at Creative New Zealand (the national body for the creative sector) include initiatives designed to strengthen capacity to address social practice priorities. In the social sector, a historical emphasis on medical model practices in health (Ball, 2013) presents challenges for arts-based practice. A shift to a socioecological perspective alongside interest in more interdisciplinary and preventative youth development models is evident in current youth mental health policy (Youth Mental Health Project, 2012). We hope that this shift, along with further research to build on the evidence produced here will open new doors for participatory arts practice.

The current neoliberal ideologies underpinning the evidence-based movement that is gaining momentum in Aotearoa New Zealand (Deane \& Harré, 2016), raise additional concerns with respect to the evaluation of participatory arts endeavours. The need to demonstrate that projects such as Express Yourself are evidence-based is challenging when the narrow forms of evidence advanced within this global movement are acknowledged to stem from positivistic notions that are disconnected from methodologies that are better suited to capture complex, culturally aligned and individualised approaches (Trickett, 2015) found in participatory arts practice. We therefore also require greater advocacy for creative and nuanced evaluation methodologies in the national evidencebased policy making context.

\section{Practice implications}

Our findings suggest that arts-based methods offer unique qualities to address current priorities in youth mental health, specifically calls for accessible, youthfriendly, culturally-attuned approaches; prevention approaches and trialling youth development models which build resilience and social connectedness (Youth Health Report, 2012). We argue that the arts offer promising applications, which could be used to bring new languages for communication and a youthful lens to more institutional environments. For example, greater effort should be placed on allowing young people to actively tell their own stories and share ideas using images, music, film and poetry in a manner that, as shown in this research, demonstrates commitment to rebalancing adult-youth power dynamics. This may aid to position youth as active partners rather than recipients in social interventions. Cahill and Coffey (2015) assert the importance of positioning in change models, and suggest that, in order to re-position young people from reluctant sites of change (clients, service users and patients) into active agents in their own change process, we need to be more attentive to positioning and offer meaningful opportunities for critical engagement and critique of the factors at play. 


\section{Conclusion}

The youth voices captured in this study suggest that participatory arts experiences offer specific qualities that resonate with young people's needs in a way that stands in stark contrast to their experience of other support services. In this way, their engagement in art-making can have a notable impact on their mental health and wellbeing. Although these voices are contained within a single case example of participatory arts engagement, their alignment with the growing international evidence base indicates that further investment in research, policy and practice in this field is warranted in Aotearoa New Zealand.

\section{References}

ACE. (2014). The value of arts and culture to people and society. London, England: Arts Council England.

Ball, J. (2010). Review of evidence about the effectiveness of mental health promotion programmes targeting youth/ rangatahi. Auckland: Mental Health Foundation of New Zealand. Retrieved from www.mentalhealth.org.nz/assets/ ResourceFinder/Review-ofevidence-about-effectiveness-ofmental-health-promotion-programmes-targetingyouth.pdf

Braun, V., \& Clarke, V. (2013). Successful qualitative research: A practical guide for beginners. London, United Kingdom: Sage.

Bungay, H., \& Vella-Burrows, T. (2013). The effects of participating in creative activities on the health and wellbeing of children and young people: A rapid review of the literature. Perspectives in Public Health, 133, 44-52. doi:10.1177/1757913912466946

Cahill, H., \& Coffey, J. (2015). Positioning, participation, and possibility: Using post-structural concepts for social change in Asia Pacific youth HIV prevention. Journal of Youth Studies. 19(4), 533-551. doi:10.1080/13676261.2 015.1083960

Clift, S. (2012). Creative arts as a public health resource: Moving from practice-based research to evidence-based practice. Perspectives in Public Health, 132(3), 120-127. doi:10.1177/1757913912442269

Clift, S., \& Camic, P. (2016). Oxford textbook of creative arts, health, and wellbeing: International perspectives on practice, policy and research. Oxford, United Kingdom: Oxford University Press.

Craemer, R. (2009). The arts and health: From economic theory to cost-effectiveness. UNESCO Observatory e-Journal, 1(4). Retrieved from http://education.unimelb. edu.au/_data/assets/pdf_file/0003/1105815/craemer.pdf

\section{ACKNOWLEDGEMENTS}

We would like to thank

Toi Ora (our case study partner) and all the young people involved in this research, without whom, it would not have been possible.
Department Health. (2007). Report of the review of arts and health working party. London, United Kingdom: Department of Health.

Department Health. (2011). No health without mental health: A cross-government mental health outcomes strategy for people of all ages. Retrieved from: https://www.gov.uk/ government/uploads/system/uploads/attachment_data/ file/213761/dh_124058.pdf

Durie, M. (1985). A Māori perspective of health. Social Science \& Medicine, 20(5), 483-486.

Hacking, S., Secker, J., Spandler, H., Kent, L., \& Shenton, J. (2008). Evaluating the impact of participatory art projects for people with mental health needs. Health \& Social Care in the Community, 16(6), 638-648.

Hickey-Moody, A. (2013). Youth, arts and education: Reassembling subjectivity through affect. London, United Kingdom; New York, NY: Routledge.

ICH (Institute for Creative Health) (2013b). Framework. Retrieved from http://www.instituteforcreativehealth.org. au/resources/australian-national-arts-health-framework

Ings, R., Crane, N., \& Cameron, M. (2012). Be creative, be well: Arts, wellbeing and local communities: An evaluation. London, England: Arts Council England.

Lerner, J. V., Bowers, E. P., Minor, K., Boyd, M. J., Mueller, M. K., Schmid, K. L., ... Lerner, R. M. (2012). Positive youth development: Processes, philosophies and programs. In I. B. Weiner, R. M. Lerner, A. Easterbrooks, \& J. Mistry (Eds.), Handbook of psychology: Developmental psychology, 2nd ed.(pp. 365-392). Hoboken, NJ: Wiley.

MacPherson, H., Hart, A., \& Heaver, B. (2015). Building resilience through group visual arts activities: Findings from a scoping study with young people experiencing mental health complexities and/or learning difficulties. Journal of Social Work, 16(5) 541-560.

Maunder, P. (2013). Rebellious mirrors: Community based theatre in Aotearoa New Zealand. Christchurch, New Zealand: Canterbury University Press.

McGorry, P., Bates T., \& Birchwood M. (2013). Designing youth mental health services for the 21st century: Examples from Australia, Ireland and the UK. The British Journal of Psychiatry, 202, s30-s35. doi:10.1192/bjp. bp.112.119214

O'Connor, P. (2014). Applied theatre: Applied social work in New Zealand. In W. H. Chiu (Ed.), School social work: Current practice and research (pp. 77-92). New York, NY: Nova Science.

Pegasus Health Ltd. (2014). The arts and health: Evidence from the international literature. New Zealand: Pegasus Health.

Pulotu-Endemann, F. K. (2001). Fonofale model of health. Retrieved from http://www.hauora.co.nz/resources/ Fonofalemodelexplanation.pdf

Putland, C. (2012). Arts and health - A guide to the evidence. Background document prepared for the Arts and Health Foundation Australia. Retrieved from http://www. instituteforcreativehealth.org.au/research/arts-andhealth-\%E2\%80\%93-guide-evidence

Sanders, J., \& Munford, R. (2014). Youth-centred practice: Positive youth development practices and pathways to better outcomes for vulnerable youth. Children and Youth Services Review, 46, 160-167. doi:10.1016/j. childyouth.2014.08.020 
Secker, J., Hacking, S., Spandler, H., Kent, L., \& Shenton, J. (2007). Mental health, social inclusion and arts: Developing the evidence base. Chelmsford, England: Anglia Ruskin University.

Trickett, E. (2015). Seymour Sarason remembered: "Plus ca change...", Psychology misdirected, and "Community psychology and the anarchist insight". American Journal of Community Psychology, 56(3), 197-204. doi:10.1007/ s10464-015-9744-9

Ungar, M. (2012). Ed. An interview with Arn Chorn-Pond: Helping children in Cambodia through the revival of traditional music and art. In M. Ungar, The social ecology of resilience: A handbook of theory and practice (pp. 99-108). New York, NY: Springer.

VicHealth. (2003). Creative connections: Promoting mental health and wellbeing through community arts participation. Victoria, Australia: Author. Retrieved from http://artshealthnetwork.ca/resources/creativeconnections-promoting-mental-health-and-wellbeingthrough-community-arts-particip

White, M. (2009). Arts development in community health: A social tonic. Oxford, England: Radcliffe.

White, M. (2016). The means to flourish: Arts in community health and education. In S. Clift, \& P. M. Camic (Eds.), Oxford textbook of creative arts, health, and wellbeing International perspectives on practice, policy and research (pp. 41-54). Oxford, United Kingdom: Oxford University Press

Wreford, G. (2016). Arts and health in Australia. In S. Clift, \& P. Camic (Eds.), Oxford textbook of creative arts, health, and wellbeing: International perspectives on practice, policy and research (pp. 135-143). Oxford, United Kingdom: Oxford University Press

Youth Mental Health Project. (2012). Retrieved from http:// www.health.govt.nz/our-work/mental-health-andaddictions/youth-mental-health-project 